\title{
Separate concreting in the construction of monolithic buildings with rubble concrete
}

\author{
Artur Mukhambetgaliev ${ }^{1, *}$, and Sergey Sinenko ${ }^{1}$ \\ ${ }^{1}$ Moscow State University of Civil Engineering, 129337, 26, Yaroslavskoye Shosse, Moscow, Russia
}

\begin{abstract}
This article describes possible solutions to this problem using recycled building materials. Three approaches to choosing an optimum organisational and technological solution are presented, compared, and analysed. A chart is given for choosing the organisational and technological solution to erect a building. The most promising approach to finding an optimum is highlighted. It is modelling of the construction of buildings, structures, and complexes as the most effective and justified approach incorporating the best aspects of the first two and offering an opportunity to accomplish the task in the most objective way.
\end{abstract}

\section{Introduction}

Providing high-quality accommodations for large numbers of residents within the established deadlines is a task that requires the use of a great volume of building materials. Houses are planned for construction using monolithic and prefabricated structures.

Governmental Decree No.493-PP dated August 1, 2017 approved the Renovation Program. Its main focus is on the improvement of the national housing per capita rate. Pursuant to this Decree, in the Southeast Administrative District alone 516 houses were included in the list of multi-apartment buildings scheduled for renovation.

\section{Materials and Methods}

It is proposed to use recycled crushed stone that can compete with natural crushed stone due to the use of efficient waste processing technology schemes and advanced equipment and improving the quality of broken concrete aggregate.

Additionally, demolition and dismantling of brick building structures can produce raw materials for use in the integrated technology of monolithic structure construction by the prepacked concreting method.[1-9] All techniques of this kind make it possible to improve the efficiency of construction and solve some of the problems associated with the need for building materials, apply simple technologies for construction and installation works. In the end, get rid of construction waste.

\footnotetext{
* Corresponding author: aljurgaitis@gmail.com
} 
Residents of the houses scheduled for renovation must be provided with comfortable living conditions. With this purpose in mind, there are plans for construction of microdistricts with a private public zone.

It is proposed to use rubble concrete for the following types of works in this construction:

- Subbase installation for access and rarely used roads;

- Foundations for warehouses, production premises and small-size machinery;

- Foundations or surfacing of pedestrian walkways, car parking lots, walk alleys, river and channel banks;

- Mixing of concrete to be used in pedestrian walkways and carpark internal ground.

Rubble concrete proposed for renovation works offers the following advantages:

- Reduced construction costs due to the use of concrete waste;

- Improved strength characteristics of a structure or a part thereof;

- Simple construction technologies;

- Use of environment-friendly materials;

- Low moisture pick-up by structures due to the use of stone materials with a low hydroscopic capacity;

- Architectural expressiveness and attractiveness.

Research in the use of concrete waste originated in the EC countries, specifically, the Netherlands, Germany, and Belgium. It was focused both on the study of concrete waste properties and various vibratory screening instruments and crushing equipment such as jaw, gyratory cone, impact or rotor hammer crushers [2-5].

Special emphasis in Germany, the US, Japan and other countries, including the Russian Federation, is laid on developing highly efficient production equipment. Crushing is divided into primary and secondary stages. Jaw and hammer equipment is used at the primary stage, while secondary crushing is performed by jaw, hammer or gyratory cone crushers and screens. Metal inclusions are extracted by various electromagnets.

Rubble concrete is composed of mortar or concrete mix and stone materials.

Advancement of technology offers innovative approaches to the construction of monolithic structures using various types of concrete pumps, including pressure (concrete) pumps.

\section{Results}

According to the findings of analysis of national and international experience in construction of monolithic structures of buildings and related facilities, the prepacked concreting method based on the use of larger fraction stone materials (granite, basalt, marble, etc.) can be used in conjunction with flow concrete or mortar mix pumped at a certain pressure to previously laid (crushed) stone with a fraction of $150-500 \mathrm{~mm}$ by the pressure method. In this case stone materials play the role of a bonding material and impart strength and durability to the monolithic structure [6-7].

Extensive on-site and laboratory research carried out by Moscow State University of Civil Engineering in the last ten years suggests the expedience of the integrated prepacked concreting method and the use of sizeable stone materials and flow concrete or mortar mix at the ratio of $80 \%$ stones and $20 \%$ mix in monolithic structures [8].

This method can be of particular relevance in the construction of monolithic strip and pier footings, bored piles and rolled well piles, on solid earth, clay, loam or black soil foundations.

Trenching in the ground dominated by the above-mentioned soils is performed by rotary excavators or manually (in low-rising construction projects). Geometrical parameters of 
trenches are determined by the design. After completion, the trench is filled up with concrete [6].

This method reduces the overall labor intensity of the technical process as it eliminates the need for large scale crushing of stone materials to the fractions of 5-10 $\mathrm{mm}$ and 10-20 $\mathrm{mm}$.

In terms of technology, rubble concrete is used in the construction of foundations as follows: all measured mix components are placed in a mixing unit and mixed thoroughly. Then design reference marks are set out in-situ and a trench is excavated. A sand and stone cushion is laid on the trench bottom with subsequent compaction and watering. Following completion of waterproofing, formwork is prepared and installed. Then concrete mix is poured in with stone materials added to its liquid layer. After that air should be removed and displacer should be added with subsequent concrete mix pumping. Mix should completely fill in the spaces between stones. Rubble concrete gains strength within 28 days on a par with monolithic strip foundations made of flow concrete mix [7].

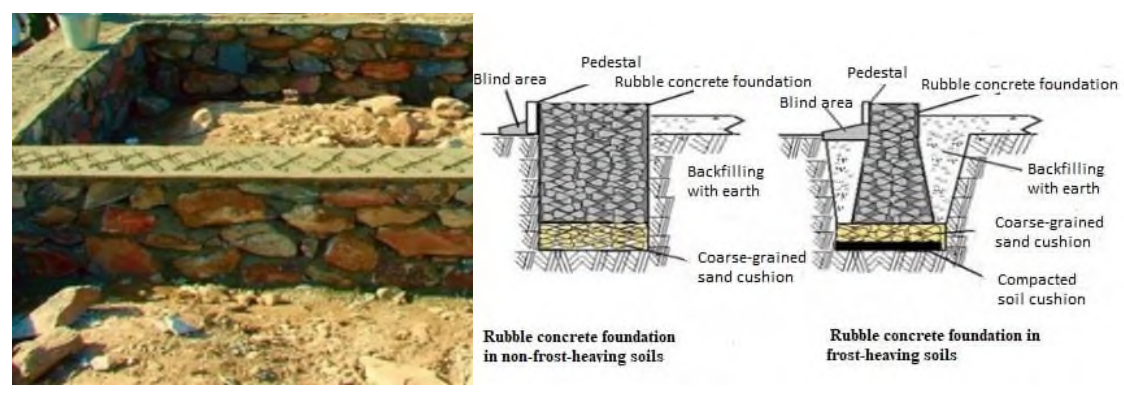

Fig 1. A rubble concrete strip foundation made by the prepacked concreting method

Rubble concrete can be efficiently used in the construction of lower-level or basement walls. Foundation depth under basement walls may not be less than $50 \mathrm{~cm}$ from the basement floor level. Planed board casing is recommended in order to avoid additional finishing.

If no casing is available, the inner surfaces of walls and window and door openings should be brick-faced half a brick thick.

In high humidity soils or soils with ground water, coating or membrane waterproofing of exterior basement walls is performed [9-10].
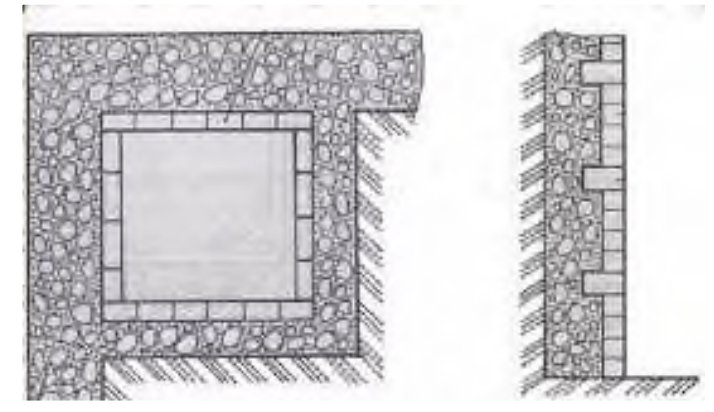

Fig 2. Monolithic rubble concrete basement walls made by the prepacked concreting method and faced with red brick

Rubble concrete is also recommended for construction of bored piles. Such piles are usually not longer than 3 meters and used in low-rising construction projects. Rubble 
concrete piles are a variety of bored piles. Stones added to the concrete mix in a rubble concrete pile with the aid of tightening weight improve the pile's compression endurance performance and reduce costs due to the use of construction waste. Rubble concrete bored piles may not be used in frost-heaving soils because they can resist axial compression loads only. A well diameter may not be less than $50 \mathrm{~cm}$.

In terms of technology, rubble concrete bored piles are constructed by the prepacked concreting method as follows. Following removal of the vegetation layer, pile design marks are set out with no allowed deviations exceeded. Soil under the pile foundation is compacted, and a sand or sand and broken stone cushion is laid and compacted. Rubble concrete is laid in the following sequence:

- A concrete delivery pipe is installed;

- The first concrete mix layer is delivered (laid) [11];

- Large-fraction aggregate is added and compacted by a tamping device;

- Mortar or fine grain flow concrete mix is delivered at pressure to the full height of the pile.

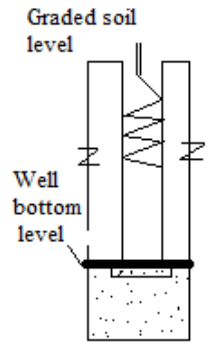

1

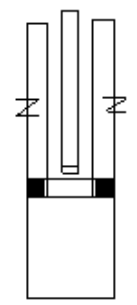

2

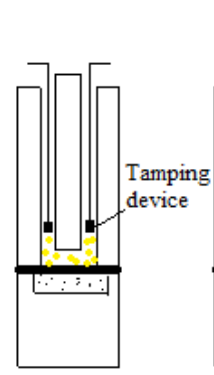

3

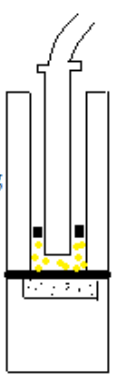

4

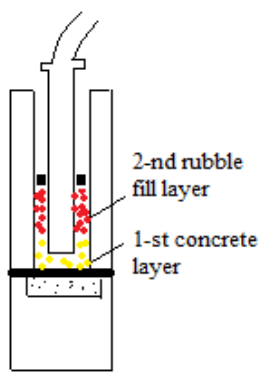

Fig 3. Construction of cast-in-place rubble concrete piles by the prepacked and pressurized concreting method. 1. Well drilling. 2. Pressure pipe installation. 3. Large-fraction stone filling and compacting by a tamping device. 4. Delivery of mortar or fine grain flow concrete mix at pressure.

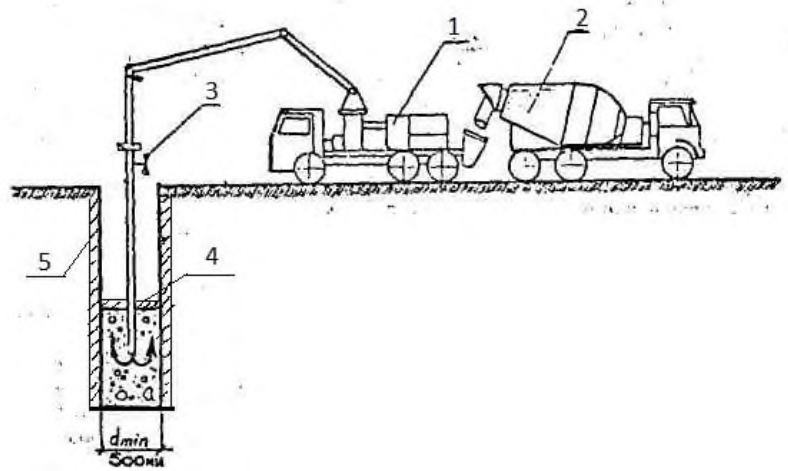

Fig 4. Construction of a cast-in-place pile for a strip foundation and a foundation slab: 1- truckmounted concrete pump; 2 - concrete mixer truck; 3 - concrete conveying pipe terminal with a diameter of 125-150 mm; 4 - tamping; 5 - compacted well walls

Rubble concrete is also extensively used in the construction of freestanding foundations used for:

- Beam, girder or column support (Figure 5); 


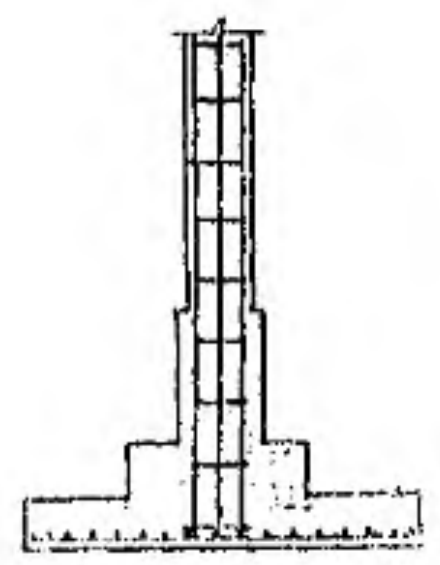

Fig. 5. Column support on a freestanding foundation

- Light load wall foundations in high density soils (Figure 6).

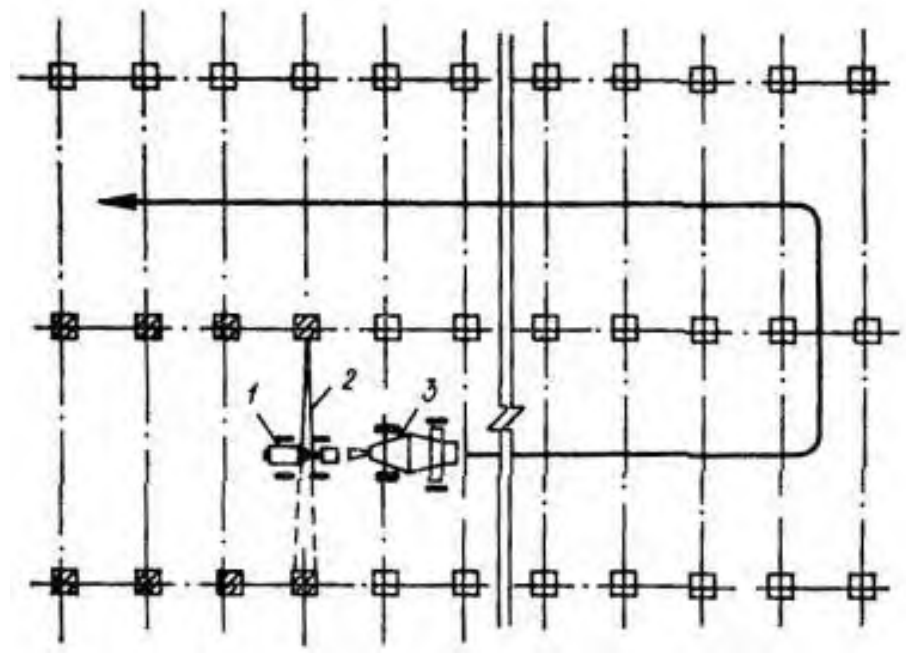

Fig. 6. A freestanding rubble concrete foundation made by the prepacked concreting method

The construction technology for freestanding rubble concrete foundations by the prepacked concreting method is similar to that for rubble concrete foundations [12].

\section{Conclusion}

This article offers a solution to the problem of shortage of building materials required for implementation of the Renovation Program as scheduled, using recycled building materials. It is proposed to use rubble concrete by the prepacked concreting method for subbase of access and rarely used roads, foundations of warehouses, production premises and smallsize machinery, foundations or surfacing of pedestrian walkways, car parking lots, walk alleys, river and channel banks, pedestrian walkways and carpark internal grounds. This article also deals with organizational and technical aspects of this construction. 


\section{References}

1. P. P. Oleynik, Organization of construction planning and managemen (Moscow, ASB Publishers, 2017)

2. B. Zhadanovsky, S. Sinenko, International Journal of Applied Engineering Research, 3, 1724-1727 (2016)

3. P. P. Oleynik, Science review, 6, 6-11 (2017)

4. B. Zhadanovsky, S. Sinenko, Advanced Materials Research, 838-841, 280-283 (2014)

5. P. P. Oleynik, Natural and Technical Sciences Journal, 10(88), 412-414 (2015)

6. S. Sinenko, T. Poznakhirko, A. Sigalov, MATEC Web of Conferences, 117, 00158 (2017)

7. I. Rozhentsova, A. Mottaeva, MATEC Web of Conferences, 106, 08076 (2017)

8. A. Lapidus, I. Abramov, MATEC Web of Conferences, 193, 05033 (2018)

9. S. Sinenko, T. Poznakhirko, MATEC Web of Conferences, 193, 05011 (2018)

10. P. Oleynik, S. Sinenko, B. Zhadanovsky, V. Brodsky, M. Kuzhin, MATEC Web of Conferences, 86, 04059 (2016)

11. P. Oleinik, A. Yurgaytis, MATEC Web of Conferences, 193, 05010 (2018), https://doi.org/10.1051/matecconf/201819305010

12. M. Rogalska, W. Bozejko, Z. Hejducki, Automation in Construction, 18, 24-31 (2008) doi:10.1016/j.autcon.2008.04.002

13. E. Vasilyeva, E3S Web of Conferences, 33, 03048 (2018)

14. I. Abramov, A. Stepanov, J. Ibrahim, Web of Conferences, 117, 00001 (2017) 